\title{
Effects on a Nearby Bridge of Dismantling Temporary Lining During Excavation of a Shallow-Buried Rectangular Tunnel
}

\author{
Guilin Sheng ${ }^{1 \dagger}$, Sen Wen ${ }^{1 * \dagger}$, Fei Wu ${ }^{1 \dagger}$, Shixing Liu $^{2 \dagger}$ and Zhengzheng Wang ${ }^{3 \dagger}$ \\ ${ }^{1}$ School of Civil Engineering and Architecture, Henan University, Kaifeng, China, ${ }^{2}$ Beijing General Municipal Engineering Design \\ and Research Institute Co., Ltd., Beijing, China, ${ }^{3}$ School of Civil Engineering, Dalian University of Technology, Dalian, China
}

OPEN ACCESS

Edited by:

Chaojun Jia,

Central South University, China

Reviewed by:

Siyuan Ma,

China Earthquake Administration,

China

Jun Yu,

Central South University, China

Yongdong Meng,

China Three Gorges University, China

*Correspondence:

Sen Wen

wsen919@126.com

tThese authors have contributed equally to this work and share first

authorship

Specialty section:

This article was submitted to

Geohazards and Georisks,

a section of the journal

Frontiers in Earth Science

Received: 27 October 2021

Accepted: 29 November 2021

Published: 14 December 2021

Citation:

Sheng G, Wen S, Wu F, Liu S and

Wang $Z$ (2021) Effects on a Nearby

Bridge of Dismantling Temporary Lining During Excavation of a Shallow-

Buried Rectangular Tunnel.

Front. Earth Sci. 9:802662.

doi: 10.3389/feart.2021.802662
It is almost inevitable that when a tunnel is excavated in an urban area, it will pass under an existing bridge. During tunnel excavation, a temporary lining is installed and subsequently removed. However, dismantling temporary lining may affect the stability of a nearby bridge. A numerical model was created and tests were conducted on a large-scale physical model to investigate the effects of dismantling temporary lining on a nearby bridge structure. A novel method of modeling the restraining force at the top of a pier was introduced to make the model more accurate in representing the physical situation. Analysis of the results led to the following conclusions and suggestions. 1. The process of removing temporary lining can have a significant impact on surface settlement and structural deformation of the bridge. 2. The effect of removing the second half temporary lining is greater than that of removing the first half. The key range of the tunnel where this phenomenon is principally observed contains one section of tunnel ahead (i.e., in the direction of tunnel advance) of the bridge span and the two sections to the rear. 3. A 6m-3 m-6m mixed dismantling method is recommended for use in the key range, and a rigid cap-connection method is proposed to counteract the considerable effects of dismantling temporary lining.

Keywords: rectangular tunnel, dismantling temporary lining, bridge substructure, tunnel excavation, settlement

\section{INTRODUCTION}

Urban tunnels are often constructed to reduce the pressure of urban traffic flow. It is sometimes unavoidable for a tunnel to pass under an existing bridge. In this situation, tunnel construction disturbs the balanced ground stress and leads to movement of the surrounding soil, which causes additional forces and consequent deformation of the bridge structure. If this potential deformation is not properly addressed, the bridge structure may suffer destructive failure, which could cause severe damage to life and property. A comprehensive understanding of tunnel-bridge interaction is necessary to ensure safety and maintain bridge stability when tunneling below a bridge. Most recent studies of interaction between tunnels and surface structures have been concerned with the effects of tunnel excavation on existing overlying structures (Chen et al., 1999; Lee and Jacobsz, 2006; Cheng et al., 2007; Lee and Chiang, 2007; Yoo, 2013; Soomro et al., 2018), although there has been some research into dismantling temporary lining.

Shallow tunnels are frequently constructed in cities. The sequential excavation method (SEM), in which the work face is divided into several temporary drifts that are individually excavated, is used because it maintains stability at the tunnel face and reduces ground surface settlement (Sharifzadeh 
et al., 2013). In this method, temporary lining is installed on drift surfaces at the time of each excavation and removed when excavation has been completed in all drifts. The temporary lining can be installed using any of a number of methods: the center diaphragm method (Seki et al., 1989), the cross-diaphragm method (Narasaki et al., 1989), the single or double side drift method (Bowers, 1997; Sharifzadeh et al., 2013), and other multidrift methods (Hoek, 2001; Li et al., 2007; Klein et al., 2008). Installation of temporary lining is an important activity in all these excavation methods but its removal may alter the bearing capacity when it is dismantled, which can be extremely dangerous for installation of the primary lining (Zhou et al., 2005). It is therefore necessary to analyze the mechanical properties and deformation of the temporary lining support (Jiang et al., 2011; $\mathrm{Hu}$ and Jin, 2015).

Lei and Zhou (2006) investigated dismantling section length for a tunnel in Nanjing. Zhang et al. (2009) combined a model with observed data and concluded that a dismantling length of $10 \mathrm{~m}$ is acceptable. Liu et al. (2014) found that a dismantling section length of $6 \mathrm{~m}$ was feasible for an upper-soft-lower-hard stratum and that dismantling had little effect on the temporary lining. Wang, (2018) identified and analyzed factors related to dismantling length and developed a model to counter their effects. Luo et al. (2017) investigated deformation of the temporary support sidewall using observed data. The preceding studies indicate the importance of the effects of dismantling temporary lining on pressure. The improvements in the technology of dismantling temporary lining and increased our understanding of the mechanical properties and deformation characteristics of a tunnel. However, the effects of dismantling temporary lining on nearby bridge structures have not been well studied, particularly for a tunnel with rectangular cross section.

This paper first describes the development and testing of a numerical model used to investigate ground surface settlement and deformation of a bridge substructure during the dismantling of temporary lining. In the numerical model, we proposed a simple but effective method to incorporate the behavior of pier tops in the model. Then we modeled the entire construction process, based on the actual construction of the tunnel, and determined the characteristics and deformations of caps and piers in the bridge structure using the numerical model. We then created an experimental physical scale model of the tunnel that in certain (scaled-down) respects was identical to the original tunnel. In experimental testing, certain indicator parameters of the numerical model were monitored, and then the data, combined with numerical model predictions, were analyzed and compared. We conclude by analyzing possible reasons to explain that removing temporary lining can have so remarkable an impact on the adjacent structure and proposing several countermeasures to provide a basis for ensuring structural safety in similar engineering projects.

\section{PROJECT BACKGROUND}

We investigated the Long-Gang road undercrossing engineering project in Shenzhen, South China. The tunnel was $6 \mathrm{~m}$ high and
$9.33 \mathrm{~m}$ wide. The various physical dimensions and the relative positions of the tunnel and bridge substructure are shown in Figure 1. The overburden was nearly $4 \mathrm{~m}$. The minimum distance between the tunnel boundary and the piles of piers 26 and 27 were respectively 9 and $5.9 \mathrm{~m}$. The piles were bearing piles with length $23 \mathrm{~m}$ and diameter $1.2 \mathrm{~m}$.

The tunnel was located in a mainly silt layer. Small pipe and large pipe shed grouting was used to reinforce strata before excavation. There were four different soil layers in this project, plain fill, silty, stone clay and breeze marble. Table 1 shows the physical and mechanical properties of in situ soil. Tunneling was conducted using the sequential excavation method. The tunnel face was divided into six small drifts, as shown in Figure 2A; Arabic numbers in the figure give the excavation sequence. The face of the upper drift was $5 \mathrm{~m}$ ahead of the face of the lower drift, and the exclusion zone was within $0.5 \mathrm{~m}$ of the face. The preliminary lining and temporary support lining were installed immediately after each drift excavation. This process was repeated cyclically until the excavation was completed. After excavation, when the preliminary lining was completed and the surrounding soil was stable, the temporary lining was dismantled. A lining-up table machine was used to dismantle the temporary lining and install the secondary lining, as shown in Figure 2B. The temporary horizontal and vertical linings were removed in $6 \mathrm{~m}$ sections (moving in the advance direction). The secondary lining was applied immediately after one tunnel section was completely dismantled. The dismantling and lining operation was resumed in the next section when the secondary lining had reached $70 \%$ ultimate strength.

\section{NUMERICAL MODELING}

\section{Model Description}

The dimensions of the finite element model, shown in Figure 3, were $60 \mathrm{~m} \times 50 \mathrm{~m} \times 30 \mathrm{~m}$. The tunnel was excavated along the Y-direction. Tunnel cross-section dimensions were $10 \mathrm{~m} \times 6 \mathrm{~m}$. Overburden depth was $4 \mathrm{~m}$. The dimensions of the bridge substructure and the spatial location with respect to the tunnel were the same as those of the actual project, shown in Figure 1.

The following assumptions were made in model creation. 1) Because the water level had been lowered in advance of the project, groundwater seepage was neglected. 2) The influence of pavement load on the ground was not considered. 3) Bridge dynamic loads were applied as equal static loads. 4) Small and large pipe shed grouting pre-reinforcement was accommodated by increasing soil parameters around the tunnel. For boundary conditions, the left and right sides of the model were constrained in the X-direction, the front and back sides were constrained in the Y-direction, the bottom was constrained in all directions, and the top surface was free.

The soil was divided into four layers from top to bottom based on the geological survey: plain fill, silty clay, stone clay and breeze marble. The uppermost three layers were HSS constitutive models (Benz, 2006). The lowest layer (breeze marble) was a MohrCoulomb material with cohesion $51 \mathrm{kPa}$, friction angle $56^{\circ}$, and mass density $2,500 \mathrm{~kg} / \mathrm{m}^{3}$. All concrete structures (piers, piles and 

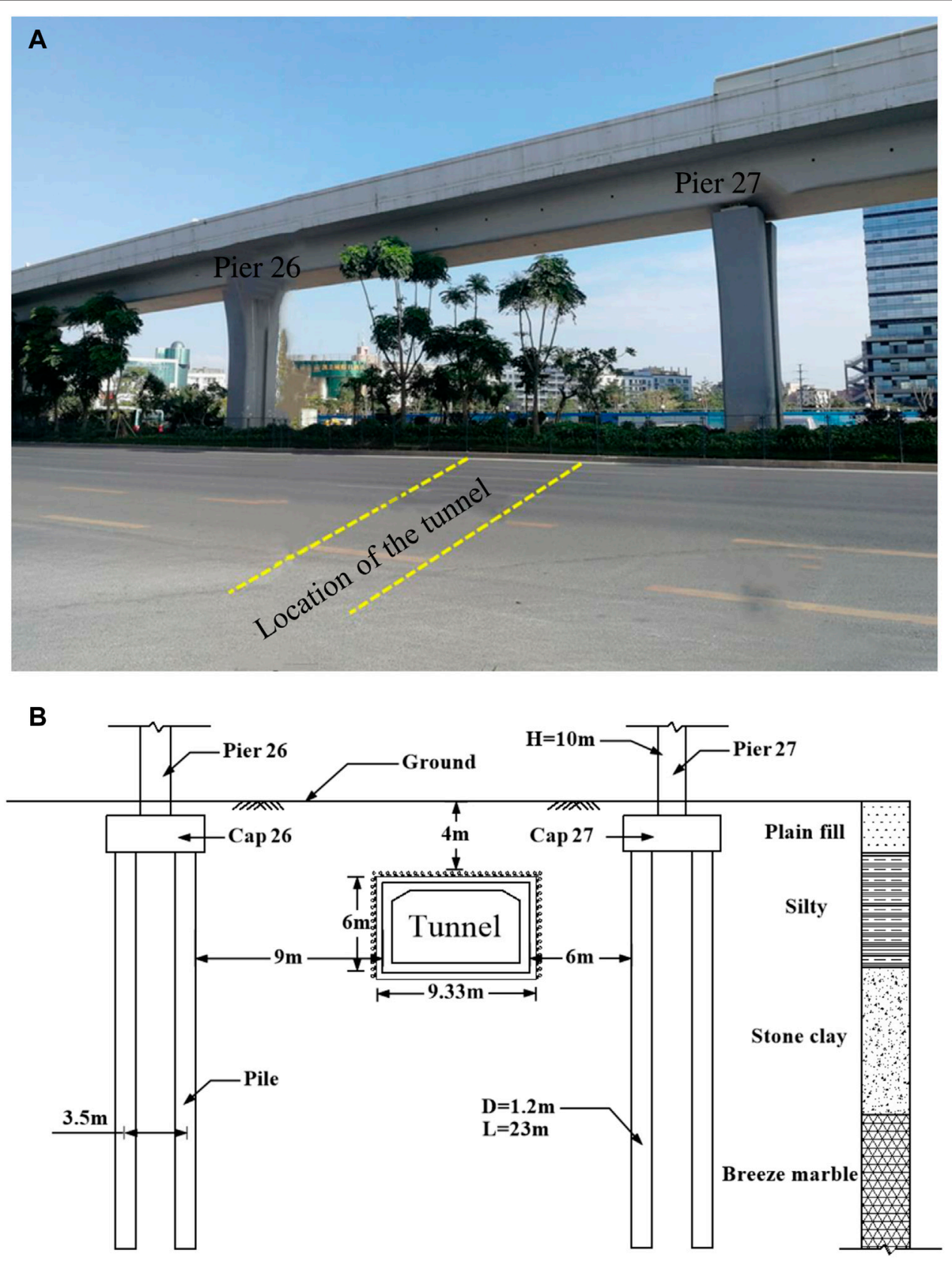

FIGURE 1 | Dimensions and relative positions of tunnel and bridge substructure: (A) Site photo; (B) Cross section.

TABLE 1 | Physical and mechanical properties of in situ soil.

\begin{tabular}{|c|c|c|c|c|c|}
\hline Soil layer & $\begin{array}{l}\text { Unit weight } \\
\left(\mathbf{k N} / \mathrm{m}^{3}\right), \gamma\end{array}$ & $\begin{array}{l}\text { Young's modulus } \\
\text { of concrete, } E \text { (MPa) }\end{array}$ & Poisson's ratio, $v_{\mathrm{c}}$ & Cohesion (kPa), c & $\begin{array}{c}\text { Internal friction } \\
\text { angle }\left({ }^{\circ}\right), \varphi\end{array}$ \\
\hline Plain fill & 18.5 & 3.92 & 0.2 & 16 & 34 \\
\hline Silty & 19.2 & 4.98 & 0.2 & 16.9 & 34 \\
\hline Stone clay & 19.2 & 5.31 & 0.2 & 17 & 34 \\
\hline Breeze marble & 25 & 34 & 0.22 & 51 & 60 \\
\hline
\end{tabular}



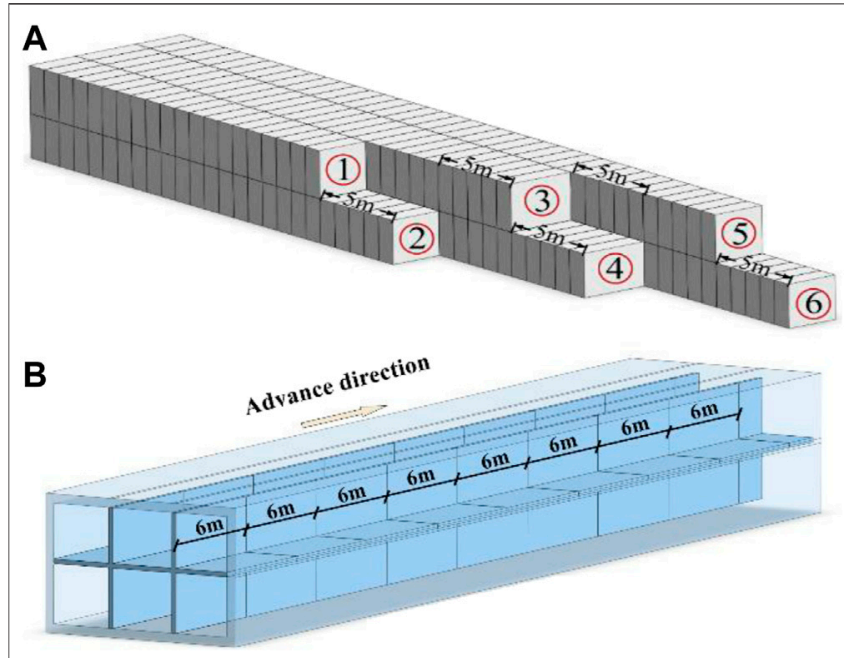

FIGURE 2 | Excavation and temporary lining dismantling method: (A) Excavation method; (B) Temporary lining dismantling method.

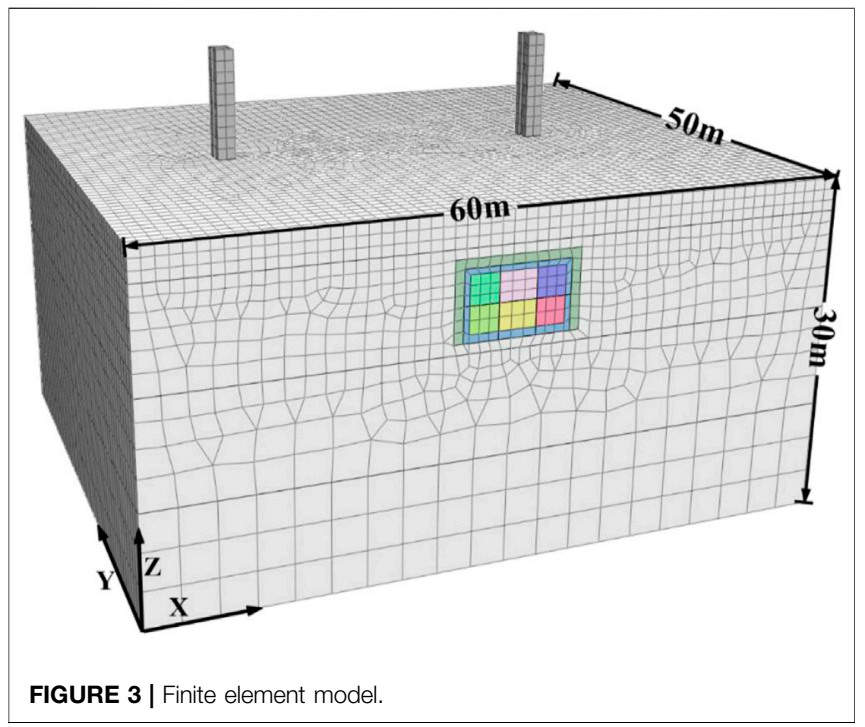

supporting structures) were elastic materials. The soil mass, bridge pier, bearing cap and secondary lining structure were all solid elements. Primary support was shell elements, and the bridge piles were beam elements. The physical and mechanical characteristics of the soil, reinforcement area, tunnel lining and bridge substructure are listed in Table 2.

\section{Model Procedure}

A simple and effective method was used to estimate the binding force at the top of the bridge pier. Tunnel construction disturbs the surrounding soil, thus affecting the bridge substructure and leading to deformation. If the bridge piers reach slipping point, the bridge bearing will provide friction to limit displacement. In practice, the binding force provided by the piers will increase during tunnel construction. When the binding force reaches the

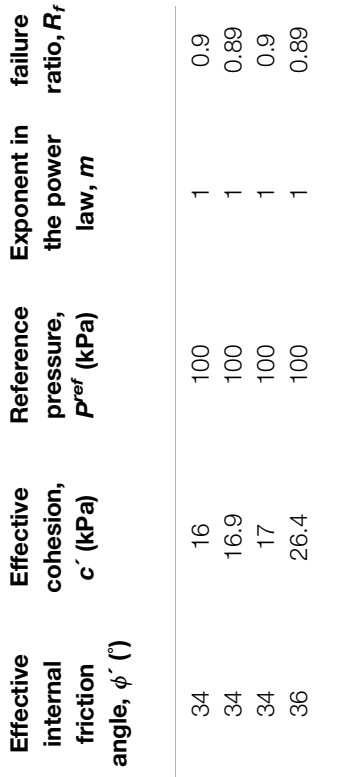

๑ึ่

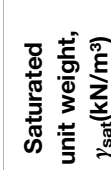

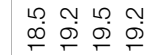

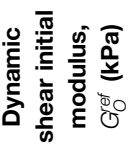

\section{8 \\ लू लू लु ल ल}

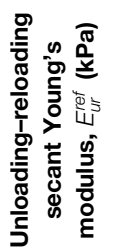

ㅇำ 8 용

ฝึ ले ले

$\begin{array}{llll}8 & 8 & 8 & 8 \\ 8 & 8 & 8 & 8 \\ \text { ले } & \text { लं } & \text { ल } & \text { ल }\end{array}$

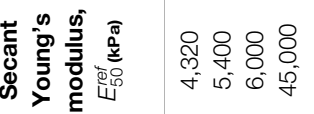

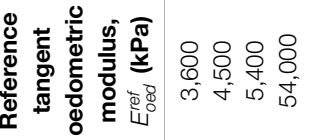

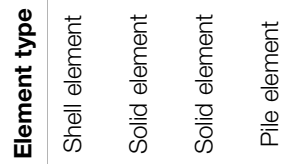

$\frac{\grave{\Phi}}{\stackrel{\bar{\sigma}}{\bar{c}}}$ 


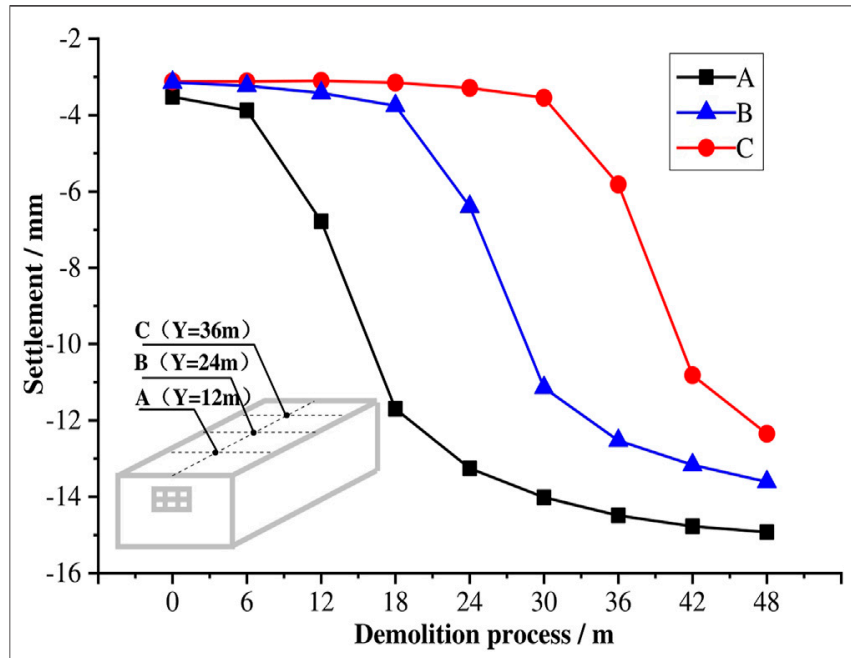

FIGURE 4 | Surface settlement during the dismantling process of temporary lining.

maximum static friction force, slipping will occur at the top of the piers, and the static friction force is converted to dynamic friction. To simulate this process, the vertical loads at the tops of the piers and the friction coefficient of the bearing were set: the load of pier 26 was $500 \mathrm{kN}$, the load of pier 27 was $270 \mathrm{kN}$, and the coefficient of friction was 0.12 for both piers. (It is easy to calculate the maximum static friction forces, which were $60 \mathrm{kN}$ for pier 26 and $32.4 \mathrm{kN}$ for pier 27). Before calculation of the numerical model, a fixed constraint was added to the element nodes of pier tops, allowing for step by step calculation of the constraining force of the piers. When the model had been calculated, the construction step corresponding to the maximum static friction force could be found. Then in the next calculation, the constraints added to the pier tops were replaced with the friction forces. Calculation then continued and produced a realistic result.

Tunnel excavation and temporary lining demolition were consistent with the practical operations shown in Figure 2, and the primary and secondary linings were applied immediately after one cycle of excavation or demolition.

\section{Numerical Model Results Surface Settlement}

Reference points A, B and C were set at the boundaries of three sections $(\mathrm{Y}=12 \mathrm{~m}, \mathrm{Y}=24 \mathrm{~m}, \mathrm{Y}=36 \mathrm{~m})$, and the tunnel invert was used to monitor settlement at these points. Figure 4 shows the settlement curves of the three reference points during the dismantling of the temporary support. Our analysis produced three major inferences drawn from our results.

Figure 4 shows that cumulative settlement for the three reference points caused by dismantling was respectively 11.4 , 10.47 and $9.23 \mathrm{~mm}$, which accounted for $76.4,76.9$ and $74.8 \%$ of the total settlement at each point. Settlement caused by dismantling was about 3 times that caused by excavation. This indicates that dismantling the temporary support significantly affected surface settlement, so more attention should be given to this process in similar projects.
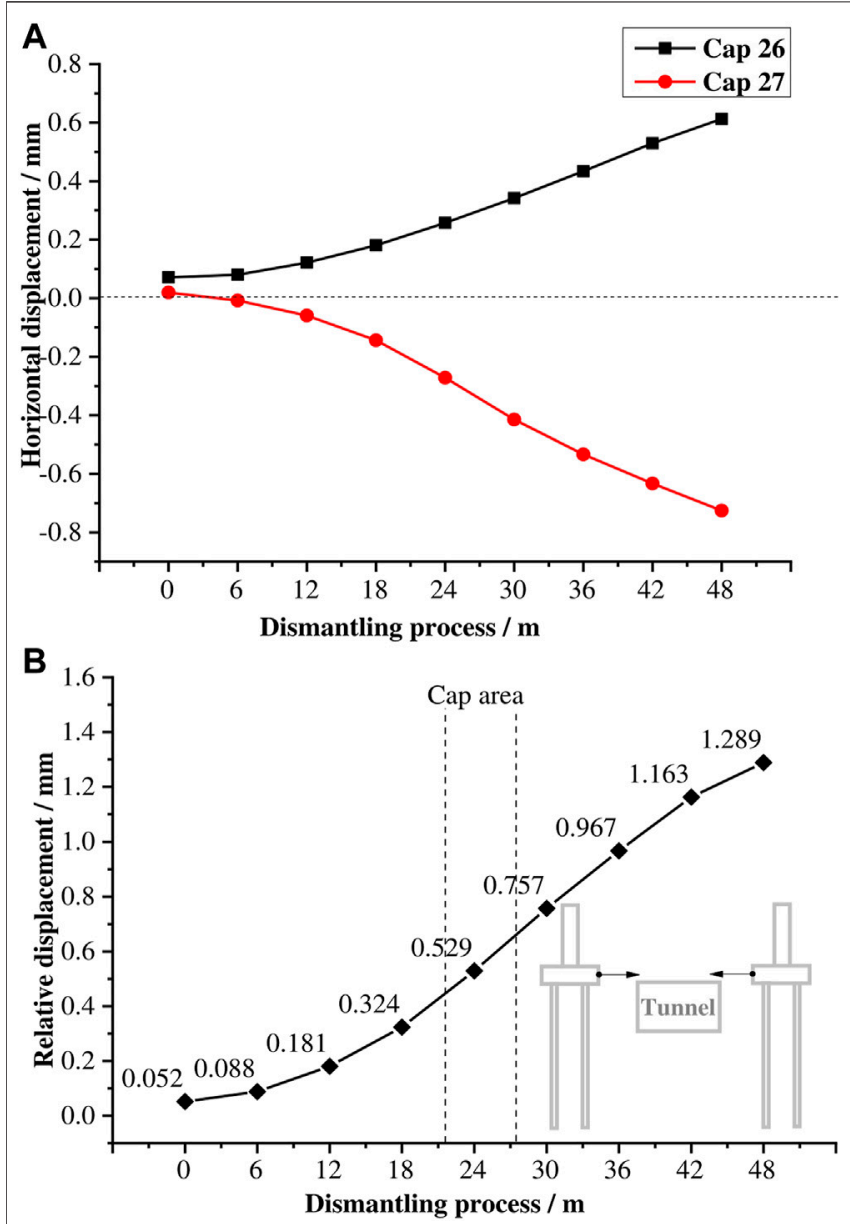

FIGURE 5 | Displacement of caps 26 and 27 during the dismantling process of temporary lining:(A) Horizontal displacement in the Y-direction; (B) Relative horizontal displacement.

Surface settlement decreased suddenly when dismantling reached the section immediately before (to the rear of) that in which a reference point was located and continued to decrease for the two subsequent sections (i.e., the range $-6 \mathrm{~m}$ to $+12 \mathrm{~m}$ ). Through this range, cumulative settlement of points $\mathrm{A}, \mathrm{B}$ and $\mathrm{C}$ was respectively $9.38,8.78$ and $8.8 \mathrm{~mm}$, which accounted for $82.28,83.86$ and $95.34 \%$ of the total settlement at each point due to demolition. This range is the key range of this process.

It can also be seen that the surface settlement within the key range caused by removing the temporary support was greater for the second half of the range than for the first half. For example, it can be seen for the curve of monitor point $B$ that when removing the temporary support in the range $0-24 \mathrm{~m}$, the accumulated settlement was $3.25 \mathrm{~mm}$ but was $7.22 \mathrm{~mm}$ in the range $24-48 \mathrm{~m}$. These two settlement values were 31 and $69 \%$ of the total settlement due to dismantling, which indicates that the bearing capacity of temporary lining is greater than that of secondary lining for the same loading conditions. It is therefore necessary to take protective measures during removal of temporary support; steel supports should be placed in the middle of the tunnel section 


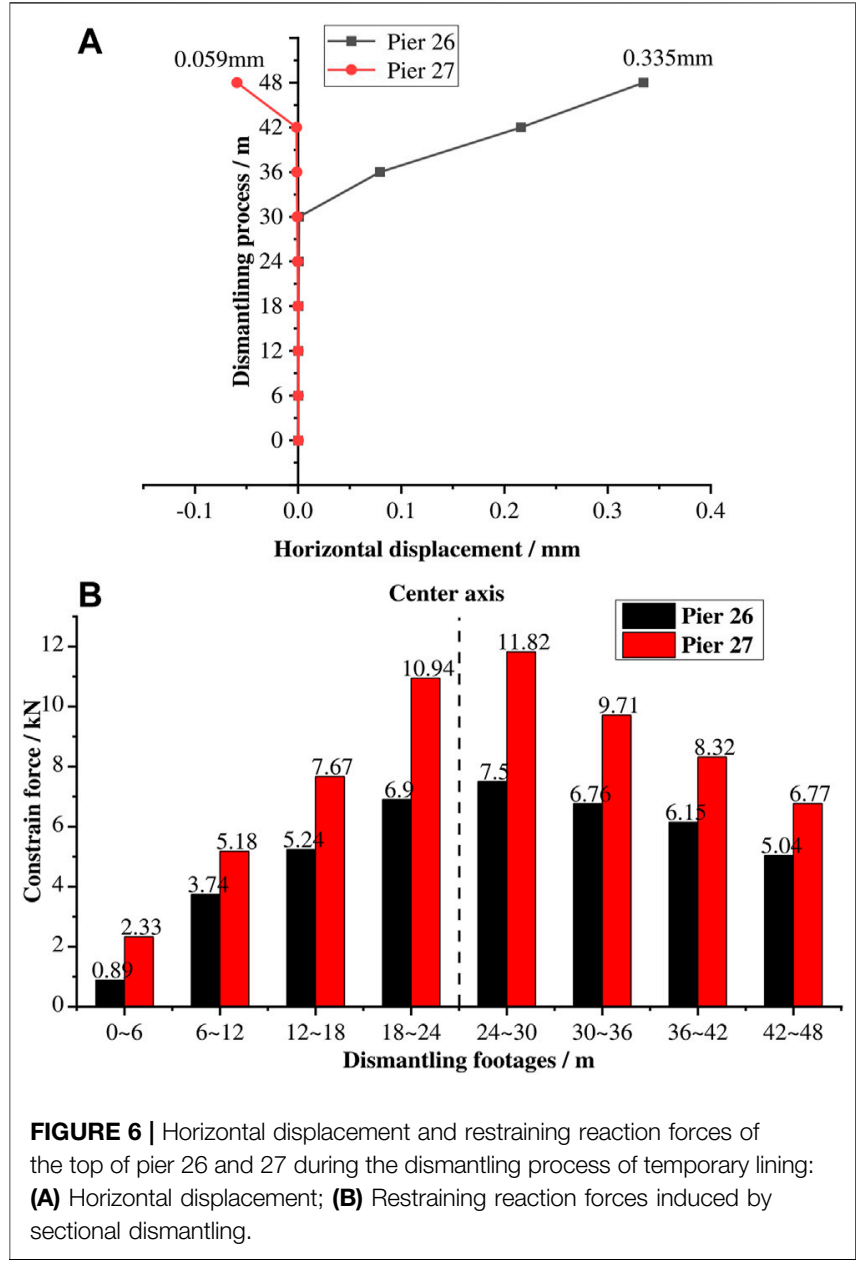

as an important safety measure when the temporary support is removed to prevent a sudden collapse due to accumulated deformation.

\section{Displacement of Pile Caps}

Figure 5A shows the horizontal displacement in the Y-direction (the direction of tunneling) of cap 26 and cap 27 during dismantling. Figure 5A shows that cap 26 was horizontally displaced by $0.597 \mathrm{~mm}$ due to removal of the temporary support and cap 27 by $0.78 \mathrm{~mm}$. These values represent 89.37 and $100 \%$ of the total displacement due to dismantling and show the significant impact of removing the temporary support on horizontal displacement of the bearing caps. The bridge caps were within $\mathrm{Y}=22.3-27.7 \mathrm{~m}$ in the direction of tunnel excavation. It can be seen from Figure 5A that the rate of displacement of the cap was greatest when dismantling temporary support in the range 18-36 m, especially for cap 27. In this range, removing one section can result in about $0.13 \mathrm{~mm}$ settlement, which is about 1.48 times the average settlement caused by one section $(0.088 \mathrm{~mm} / \mathrm{section})$. The cumulative horizontal displacement of cap 27 was $0.393 \mathrm{~mm}$, which was $50.8 \%$ of the total displacement of the cap.
Figure 5B shows the relative change in horizontal displacement in the X-direction of the two caps during dismantling. The total relative horizontal displacement of the caps was $1.289 \mathrm{~mm}$ (allowed $2 \mathrm{~mm}$ ), and the rate of increase in relative horizontal displacement was greatest when $\mathrm{Y}$ was in the range $18-36 \mathrm{~m}$. It can therefore be taken that the range of key influence on the bearing cap for dismantling temporary support was $Y=18-36 \mathrm{~m}$. The scope is one section ahead and two sections to the rear of the central section of the bridge cap area, which is consistent with the conclusion formed in Surface Settlement.

\section{Horizontal Displacement of Piers and Pier Tops}

Figure 6A show the displacement of the pier tops during the dismantling process of temporary lining. The movement of each pier can be divided into two stages. In the first stage, the pier top was stationary during tunnel excavation. This was because the force caused by tunnel construction was less than the maximum static friction force provided by the bridge bearing. The two piers remained stationary during the excavation due to the constraining effect of the pier tops; thus the extra force caused in this stage was not enough to move the pier tops.

The second stage is the slipping of the piers. Figure 6A show that the top of pier 26 began to slip during temporary lining removal in section $30 \mathrm{~m}-36 \mathrm{~m}$, and the top of pier 27 began to slip in temporary lining removal in section $42 \mathrm{~m}-48 \mathrm{~m}$. The final horizontal displacements were respectively $0.335 \mathrm{~mm}$ and $-0.059 \mathrm{~mm}$. Pier 27 began to slip after pier 26 because the binding force at the top of pier 27 was greater than that of pier 26 .

Figure 6B shows the restraining reaction forces at the tops of the two piers due to the dismantling of temporary lining in each section. The restraining reaction force caused by removal of the temporary supports on the top of pier 26 was $42.22 \mathrm{kN}$ and on the top of pier 27 was $62.74 \mathrm{kN}$. These values indicate that the pier structure that is closer to the tunnel excavation area is more likely disturbed by tunnel construction than the more distant pier. When removing the temporary lining in sections in the range $18-36 \mathrm{~m}$, the restraining reaction forces on the two piers were the most significant forces. The restraining reaction force at the top of pier 26 was $21.16 \mathrm{kN}$ and at the top of pier 27 was $32.47 \mathrm{kN}$; these values represent 50.12 and $51.75 \%$ of the total force for each pier. These values indicate that the length of tunnel from one section ahead of the piers to two sections after the midpoint of the cap is the key range for similar projects. This matches our conclusion in Surface Settlement. If we take the midpoint $\mathrm{Y}=24 \mathrm{~m}$ as the point of reference, we see that the restraining reaction force of pier 26 caused by removal of temporary supports in the range $0-24 \mathrm{~m}$ was $16.77 \mathrm{kN}$ and in the range $24-48 \mathrm{~m}$ was $25.45 \mathrm{kN}$; these values represent 39.72 and $60.28 \%$ of the total force. Corresponding values for pier 27 were 21.16 and $32.47 \mathrm{kN}$, representing 41.63 and $58.36 \%$ of the total force. These results indicate that removal of temporary support to the rear of the midpoint always has a greater effect than removal of temporary support ahead of the midpoint.

\section{Deformation Characteristics of Bridge Piles}

The numerical model was used to investigate the effects of removing tunnel support on piles supporting the cap that are 


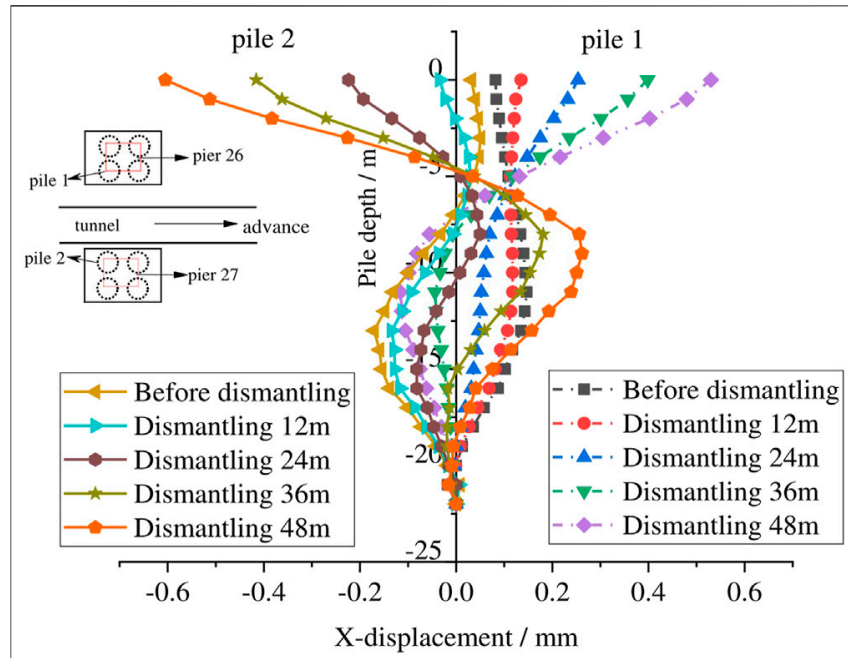

FIGURE 7 | Displacement of pile 1 and 2 in the X-direction during dismantling.

subjected to frictional force and bridge bearing load. Two typical piles are shown as pile 1 and pile 2, supporting piers 26 and 27, in Figure 7. We examined deformation during the removal of temporary support. Displacements of piles 1 and 2 in the $\mathrm{X}$-direction during dismantling are shown in Figure 7.

Pile deformation varied considerably during the removal of temporary support. The deformation trend of pile 1 was similar to that of pile 2 . In the depth range $0 \mathrm{~m}$ to $-5 \mathrm{~m}$, the piles are displaced towards the tunnel but in the range $-5 \mathrm{~m}$ to $-20 \mathrm{~m}$, deformation was initially towards the tunnel and then gradually away from the tunnel as the temporary support was removed. The point of inflexion was at $-5 \mathrm{~m}$ depth; at this point there was almost no change in displacement.

Deformation decreased as the pile-tunnel distance increased. Maximum displacement occurred at the tops of the piles: $0.53 \mathrm{~mm}$ for pile 1 and $0.605 \mathrm{~mm}$ for pile 2 in the direction of the tunnel position. Maximum displacement away from the tunnel occurred around the depth of $10 \mathrm{~m}: 0.116 \mathrm{~mm}$ for pile 1 and $0.262 \mathrm{~mm}$ for pile 2 .

\section{EXPERIMENTAL COMPARISON}

\section{Model Description and Testing, Measurement}

The physical model must be measurably similar to the numerical model in certain aspects, such as geometry, physical mechanical properties, boundary conditions and stress conditions (Zhang et al., 2008; Shi, 2014). Geometric similarity was in the ratio $10: 1$; bulk density was similar in the ratio 1:1; and the internal dimensions of the model tunnel were $6 \mathrm{~m}$ (length) $\times 2 \mathrm{~m}$ (width) $\times 2 \mathrm{~m}$ (height). Figure 8A shows the experimental model.

The model box was considerably smaller than the tunnel it represented, and the in-situ soil layers were similar, so we modeled only the in situ silty clay soil layer. Barite powder and river sand were used as material being similar to the surrounding rocks, and paraffin was used as cement. The optimal ratio of river sand to barite powder to paraffin was finally determined to be 1:0.6:0.05 by multiple material tests. Table 3 shows the mechanical parameters of soil mass in the prototype engineering measured in the laboratory and similar materials in the model test, which was calculated according to similarity.

Gypsum was selected as a similar material to model the primary lining, secondary lining and the bridge structure. Static compression tests were conducted according to the standard elastic modulus test for concrete specimens to determine the proportions of concrete components. The optimal similarity ratio between prototype and model material was determined to be 1:9.7. The elastic modulus of the prototype was $31 \mathrm{GPa}$ and of the model material was $3.19 \mathrm{GPa}$.

The constraints of test conditions make it difficult to ensure model testing accurately represents the behavior of the real objects. We made a number of adjustments to the experimental configuration.

1. We modeled only the silty clay soil layer rather than the four in situ soil layers; the in-situ soil layers have similar properties and modeling each layer of soil would introduce an unnecessary complexity in modeling.

2. The constraint of laboratory space made it difficult to scale down the length of the bridge pile to the same degree as the other model components; after comprehensive consideration, the length of the bridge pile was set to $1.2 \mathrm{~m}$.

3. During the design of the experiment, no suitable method was found to model the actual force at the pier tops. Thus, in the experiment, there was no constraint on the pier tops, and the pier tops were free in the testing.

4. The depth of the model box was only $2 \mathrm{~m}$, which was not completely consistent with the numerical model. In order to investigate the effects of removing temporary support on surrounding rock and the bridge structure, the support removal section length was set to $30 \mathrm{~cm}$ for the physical model.

A displacement sensor was used to monitor surface subsidence over the entire test, and a multifunctional static strain recording instrument was used for data collection.

Change in the angles of inclination in the $\mathrm{X}-\mathrm{Z}$ plane of the bridge piers and caps caused by tunneling was measured using a MEMS acceleration attitude angle sensor.

A fiber Bragg grating sensor was used to monitor the deformation of bridge piles. The sensor was embedded in the pile and connected to the fiber Bragg grating demodulator to collect bridge pile deformation data during tunnel construction. Sensor arrangement is shown in Figures 8B,C.

\section{Experimental Process}

Test excavation was in accordance with the construction method actually used for the tunnel (Figure 2). The spacing between adjacent guide holes was $20 \mathrm{~cm}$. After one excavation section was completed, the primary support was installed. Figure 9 shows the experimental process. 


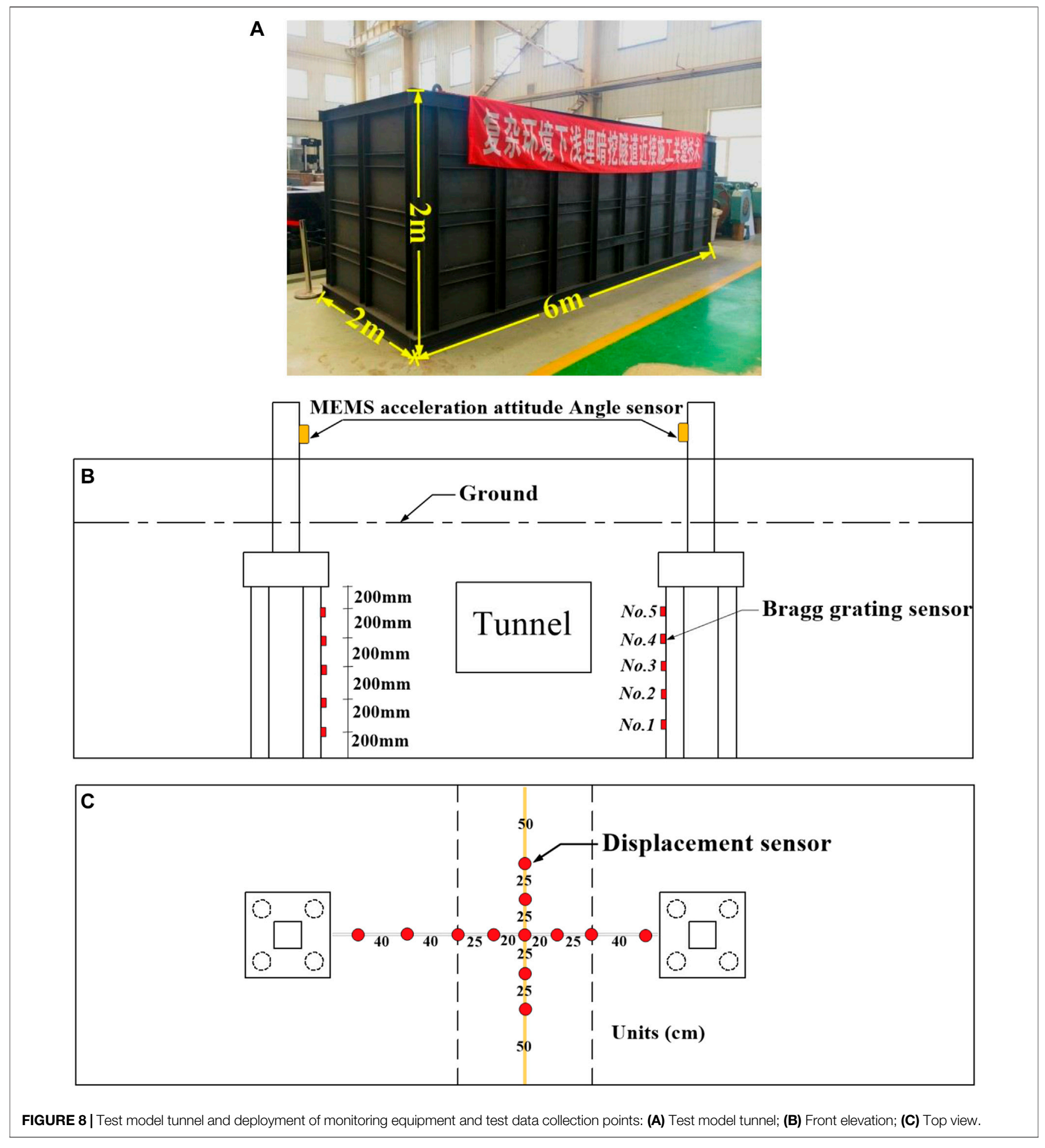

\section{Excavation and Primary Support}

When the sensors were fully operational, the work face was divided into six guide holes (drifts) for partial excavation in order 1-6. The excavation advance was $10 \mathrm{~cm}$, and the excavation faces of adjacent drifts were $30 \mathrm{~cm}$ apart. The primary support was installed immediately after excavation. When the primary support had cured, the next excavation cycle continued and so on until all drifts were excavated. 
TABLE 3 | Surrounding in situ soil and model soil parameters.

Material

Surrounding in situ soil

Model materials

Similarity ratio
Cohesive force (kPa)

24.6

2.5

9.8

Internal
friction angle ( $)$

19

31

0.6
Unit weight of soil $\left(\mathrm{kN} / \mathrm{m}^{3}\right)$

19.2

19.2

1
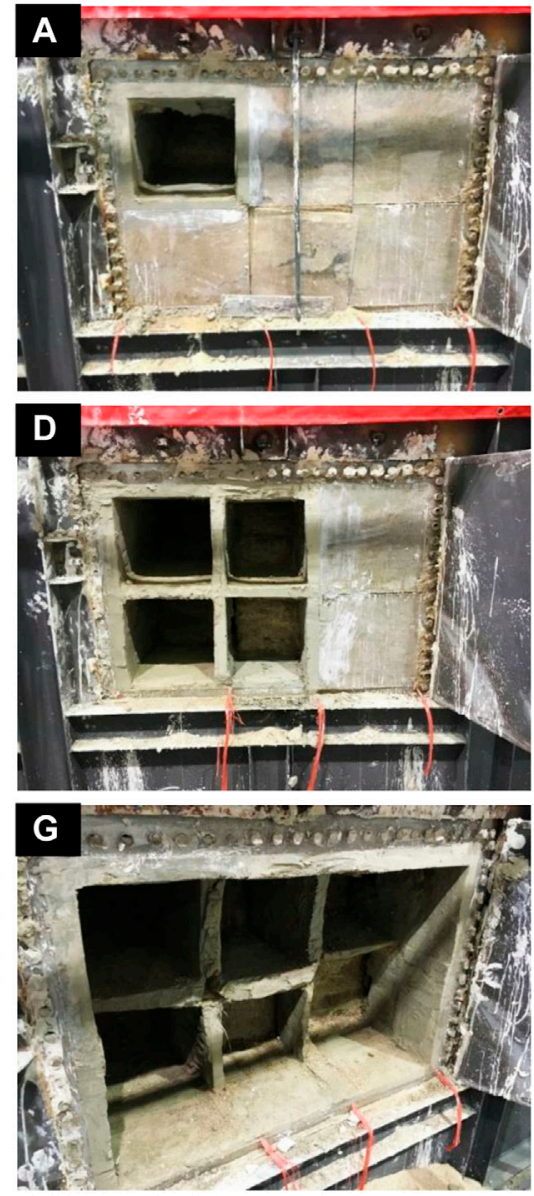
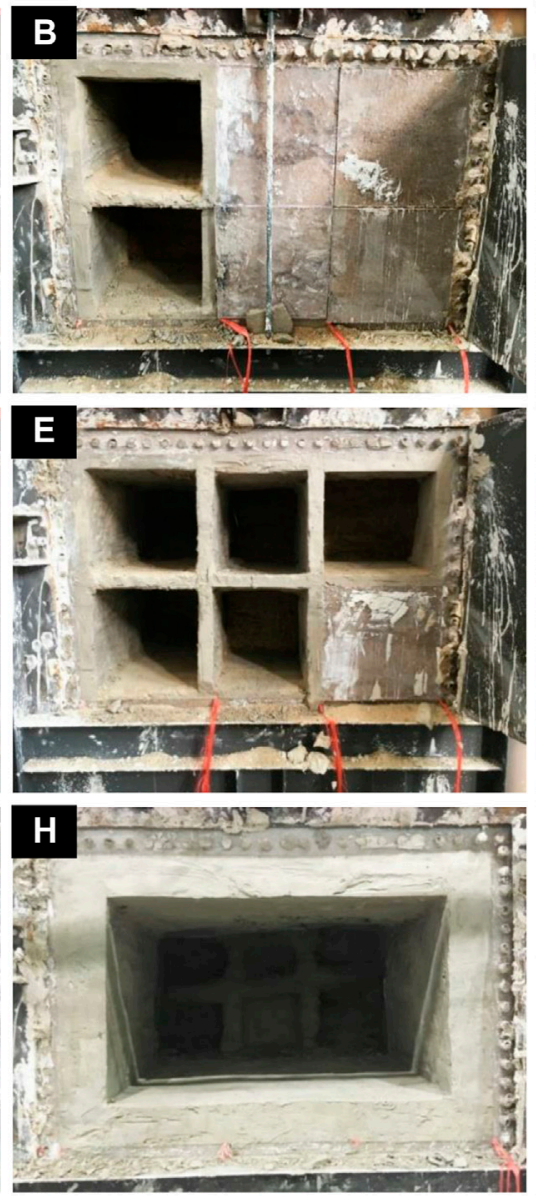
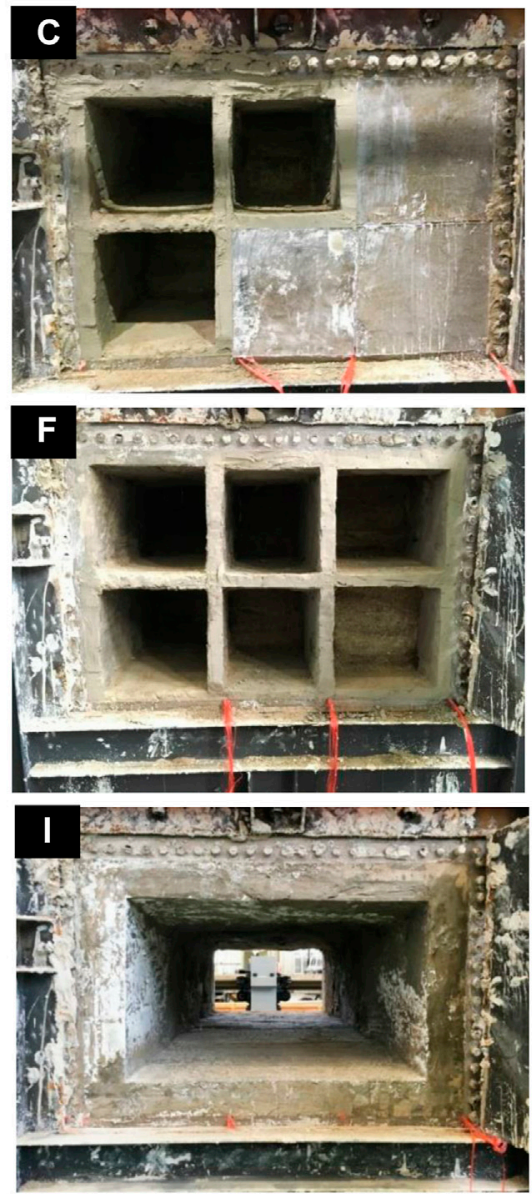

FIGURE 9 | Experimental excavation and primary lining installation: (A) Excavation of drift 1; (B) Excavation of drift 2; (C) Excavation of drift 3; (D) Excavation of drift 4; (E) Excavation of drift 5; (F) Excavation of drift 6; (G) Dismantle temporary lining; (H) Apply secondary lining; (I) Tunneling completed.

\section{Removal of Temporary Support and Installation of Secondary Lining}

When the tunnel had been completely excavated and the soil and surrounding soil displacement ceased, the temporary support was dismantled using a method similar to that used in the actual project. The temporary supports were individually removed along the advance direction in $30 \mathrm{~cm}$ stages. The secondary lining was installed immediately after removing the primary support. When the secondary lining had cured to a predetermined level, the next stage was dismantled, and so on until all the work was completed.

\section{Analysis of Test Results Ground Surface Settlement}

Three monitoring points $\mathrm{A}(\mathrm{Y}=50 \mathrm{~cm}), \mathrm{B}(\mathrm{Y}=100 \mathrm{~cm})$, and $\mathrm{C}(\mathrm{Y}$ $=150 \mathrm{~cm}$ ), which were located at the ground surface along the central axis in the Y-direction, were selected for detailed monitoring. Figure 10 shows surface settlement during the dismantling process of temporary lining.

Figure 10 shows that all three monitoring points present an overall downward trend; cumulative settlement at point $\mathrm{A}$ was $3 \mathrm{~mm}$, at point $B$ was $4.5 \mathrm{~mm}$, and at point $C$ was $5.5 \mathrm{~mm}$. These values represent respectively $78.95,70.98$ and $76.66 \%$ of total 


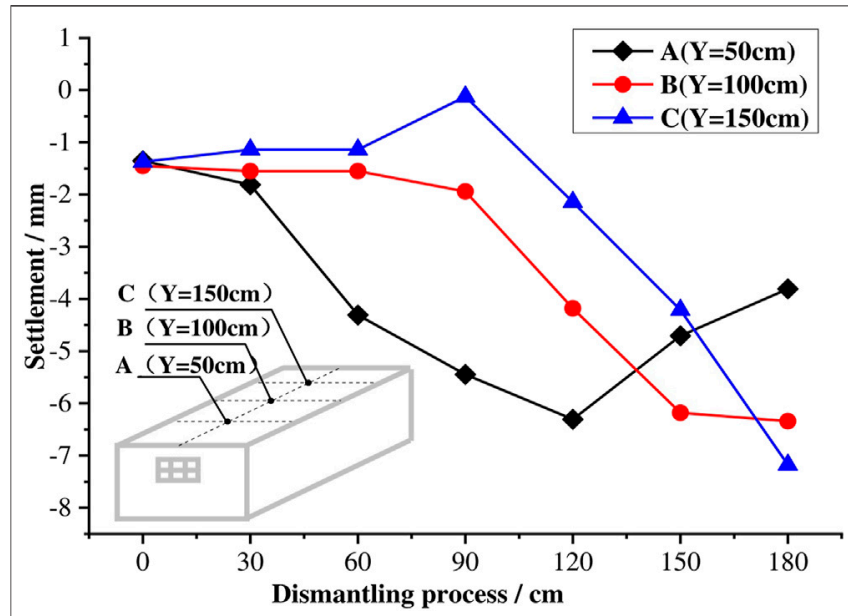

FIGURE 10 | Surface settlement during the dismantling process of temporary lining.

ground settlement at each point. The test results are consistent with the numerical model results and confirm the significant effects on surface settlement of removing temporary support. The settlement curve of point $\mathrm{B}(\mathrm{Y}=100 \mathrm{~cm})$ shows that cumulative settlement caused by removing temporary support in the range $0-100 \mathrm{~cm}$ was $2 \mathrm{~mm}$ but in the range $100-180 \mathrm{~cm}$ it was $3.5 \mathrm{~mm}$; these results represent 36.36 and $63.64 \%$ of the total settlement. This result indicates that the effects of dismantling are less at the head of the tunnel than at the rear of the tunnel, which is also consistent with the results given by the numerical model (Surface Settlement). The length of the model tunnel constrains the accuracy of identifying the extent of the influence of dismantling on surface settlement. However, it can be inferred from the three settlement curves that dismantling in one section ahead of the monitoring point and two sections to the rear of the monitoring point is the key area of maximum settlement.

\section{Deformations of Piers and Piles}

It was assumed that the trends of change in inclination for piers and caps were the same during the removal of temporary support. Figure 11A shows the angles of inclination for the piers during dismantling. The experimental results show that overall change in inclination angle for pier 26 was $0.05^{\circ}$ and for pier 27 was $0.06^{\circ}$; these values represent 57.4 and $45.1 \%$ of the total inclination of each pier and were less than the values predicted by the numerical model. This may be due to the primary support for the side wall not being close enough to the surrounding soil for the sideways soil pressure to be effectively transferred to the temporary transverse support.

The maximum inclination angles of the two piers were $0.071^{\circ}$ (pier 26) and $0.138^{\circ}$ (pier 27). This result indicates that disturbance and deformation decrease as the pier is further from the tunnel. This is not consistent with the fluctuating rate of change in inclination angle given by the numerical model. Figure 11A shows that the inclination angle curve for pier 27 fluctuates more than the curve for pier 26. This is because pier 27 is closer to the tunnel excavation area than pier 26 and
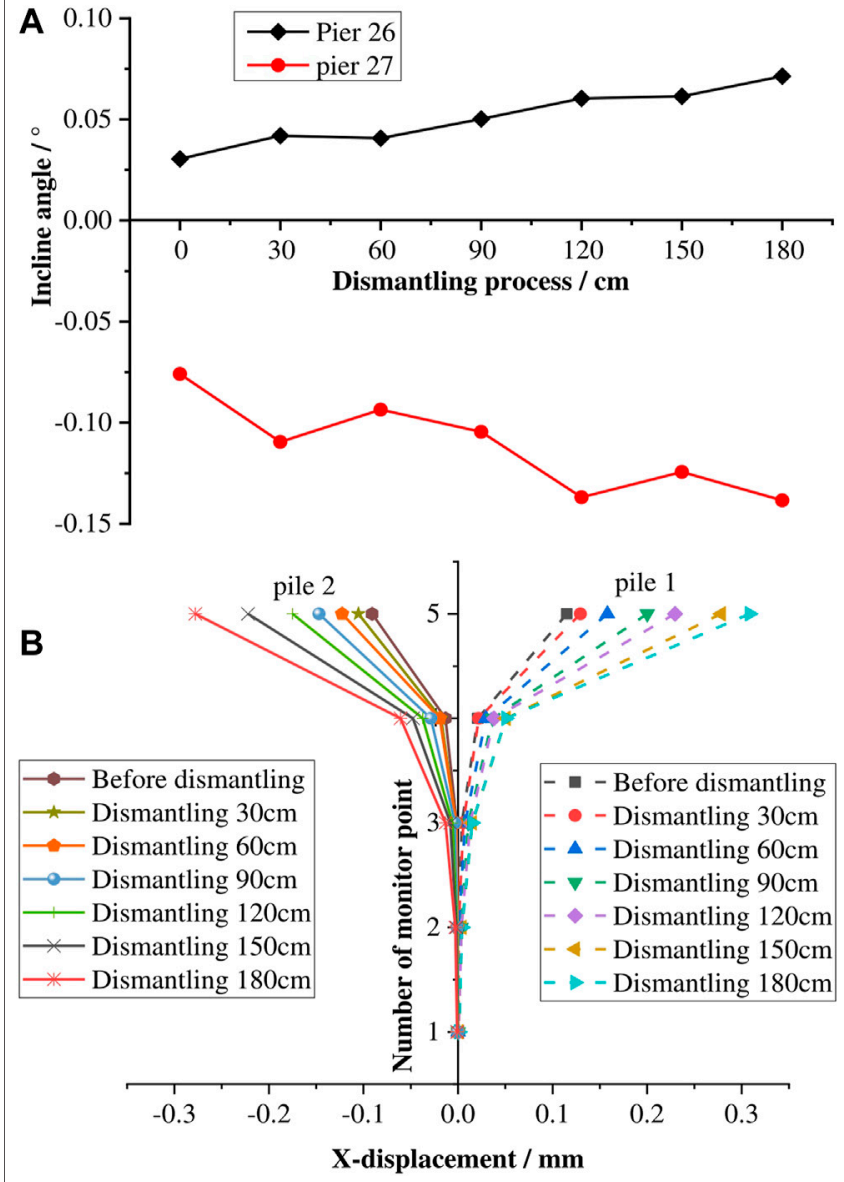

FIGURE 11 | Deformations of piers and piles during the dismantling process of temporary lining:(A) Change in inclination of piers; (B) Horizontal displacement of piles.

therefore more susceptible to the effects of the impact load generated during the dismantling process of temporary support. The regularity of the variation in the inclination angles of the bridge piers was not totally consistent with the numerical model predictions, but it can be seen that when the temporary support was removed in the range $60-120 \mathrm{~cm}$, variation in the inclination angles was $0.02^{\circ}$ (pier 26) and $0.043^{\circ}$ (pier 27); these values represent 48.81 and $68.85 \%$ of the total variation. The bridge substructure only just remained in this range, which indicates that dismantling the temporary support when close to the piles contributes significantly to pier and cap deformation.

The piles were not completely represented in the experiment due to laboratory constraints. Thus only sections of the piles and bridge structure were represented in the physical model. One pile was selected from each pier as a representative for monitoring, pile 1 from pier 26 and pile 2 from pier 27, as shown in Figure 7. Deformations of the piles as measured in the experiment are shown in Figure 11B. The greatest changes in displacement are at the top of the pile, and the maximum horizontal deformations were $0.193 \mathrm{~mm}$ (pile 1) and $0.187 \mathrm{~mm}$ (pile 2); these values 
TABLE 4 | Various reference indexes of different schemes.

\begin{tabular}{|c|c|c|c|c|c|}
\hline Scheme & $\begin{array}{l}\text { Surface settlement } \\
\qquad(\mathbf{m m})\end{array}$ & $\begin{array}{l}\text { Relative horizontal } \\
\text { displacement of } \\
\text { two caps }(\mathrm{mm})\end{array}$ & $\begin{array}{c}\text { Maximum X-displacement } \\
\text { of pier tops }(\mathrm{mm})\end{array}$ & $\begin{array}{l}\text { Maximum X- } \\
\text { displacement of } \\
\text { pile } 1(\mathrm{~mm})\end{array}$ & $\begin{array}{l}\text { Maximum X- } \\
\text { displacement of } \\
\text { pile } 2(\mathrm{~mm})\end{array}$ \\
\hline Scheme 1 & 14.1 & 1.72 & 0.98 & 0.762 & 0.922 \\
\hline Scheme 2 & 9.34 & 1.06 & 0 & 0.484 & 0.567 \\
\hline Scheme 3 & 14.1 & 0 & 0 & 0.168 & 0.241 \\
\hline
\end{tabular}

represent 62.7 and $67.3 \%$ of the total deformation. These results, like the numerical model predictions, also indicates that the removal of temporary support has a significant effect on pile deformation.

Deformation modes of the piles considered in the models were bending and inclination; deformation of the entire bridge pile is similar to that of the upper part of the pile predicted in the numerical model. Deformation of the two piles is inclined in relation to the tunnel centreline, and the greatest horizontal displacement is at the top of the pile. It can be inferred that most at-risk parts of the bridge structure are the points at which piles and caps connect because the stress concentration will occur at these points. The bridge piles were located near the $Y=100 \mathrm{~cm}$ section of the tunnel. When the temporary support in sections in the $60-150 \mathrm{~cm}$ range was removed, the horizontal displacements of the piles were $0.12 \mathrm{~mm}$ (pile 1) and $0.1 \mathrm{~mm}$ (pile 2); these values represent 40 and $37 \%$ of the total horizontal displacement. These results indicate that the removal of temporary support in sections of the tunnel that are close to the piles has a very significant effect on horizontal deformation of the bridge; the results are consistent with the numerical model predictions.

\section{DISCUSSION}

Soil is complex, heterogeneous and an experiment is constrained by the circumstances and condition under which it is conducted; neither a numerical model nor a physical model can entirely represent the real project. However, both the numerical model and the experimental results show that the removal of temporary support significantly affected the tunnel and the nearby bridge substructure: the additional effect of the dismantling operation can be over $50 \%$ of existing surface settlement and structural deformation. There are several reasons for the extent of these effects.

1) The temporary supports are important factors in the mechanical system, especially in a shallow-buried rectangular tunnel. Under the same load, deformation of a rectangular section due to construction should be paid more attention than that of circular and horseshoe sections.

2) The depth of soil covering is inadequate to form an arch. Thus, the force of the overburden acts on the top of the primary tunnel lining. In addition, the uppermost soil layer is weak, and the soil can be easily disturbed. Soil pressure can act rapidly on the primary lining to deform it.
3) Initial stiffness may be insufficient to adequately support the load. When the intermediate temporary support is removed, the load it bears is quickly transferred to adjacent support, and secondary deformation may then occur due to insufficient stiffness.

\section{COUNTERMEASURES}

We have increased our understanding of the effects of removing temporary support as they were observed in deformation of the tunnel and bridge substructure by using a numerical model and experimenting with a physical scale model. We make two suggestions for reducing these effects and improving tunnel construction security:

1. A common practice to minimize the negative effects is to reduce the demolition length per cycle along the tunnel. The results of the numerical analysis and physical model testing showed that the removal of temporary support within the key range (i.e., the range $-6 \mathrm{~m}$ to $12 \mathrm{~m}$ ) of the central section of the pier in the $\mathrm{Y}$-direction can lead to significant deformation of the bridge structure, which might then be in the danger zone for this kind of undercrossing engineering. We propose a 6 m-3 m-6 m mixed demolition method, that we defined as scheme 2, to address this problem. Changing the step size of the dismantling process to $3 \mathrm{~m}$ within the key area but maintaining the $6 \mathrm{~m}$ step outside the key area is the $6 m-3 m-6 m$ mixed dismantling method. In order to verify the superiority of this scheme, we undertook numerical analysis and compared the results with various reference indexes of the original scheme 1 . The results are shown in Table 4. It can be seen from the table that all the indicators shown (surface settlement, relative horizontal displacement of two caps, displacement of the pier tops and maximum horizontal pile displacement) were significantly decreased. This scheme can be used as a reference point for similar projects.

2. The relative displacement of adjacent caps must be strictly attended to in tunnel construction to ensure the safety of the bridge. A reusable rigid structure that connects the two adjacent caps to form an integral unit before the tunnel construction should be devised and constructed to prevent relative horizontal displacement of the two caps. This was modeled as scheme 3, shown in Table 4 , and is referred to as the rigid cap-connection method. It can be seen that all 
indexes were considerably reduced except surface settlement. This method can be used to increase the structural capacity to withstand an emergency.

\section{CONCLUSION}

In this investigation of the effects of dismantling temporary lining using a numerical model and an experimental physical scale model, we drew the following conclusions:

1) Modeling the restraining forces at the tops of the piers is a simple and effective way to make model predictions close to results obtained in practice, which means our work provides a sound basis for reference in similar projects.

2) In shallow-buried rectangular tunnel construction, removal of temporary support can increase surface settlement and bridge substructure deformation by over $50 \%$. The range from one section ahead of the bridge structures to two sections of its rear is the key range of the project. In the key range, settlement and deformation develop rapidly. Thus, activity in this range requires careful attention.

3) The $6 \mathrm{~m}-3 \mathrm{~m}-6 \mathrm{~m}$ mixed demolition method and rigid capconnection method are proposed to counter the effects of

\section{REFERENCES}

Benz, T. (2006). Small Strain Stiffness of Soils and its Numerical Consequences. Stuttgart: University of Stuttgart.

Bowers, K. H. (1997). An Appraisal of the New Austrian Tunneling Method in Soil and Weak Rock. University of leeds, 240. PhD Thesis.

Chen, L. T., Poulos, H. G., and Loganathan, N. (1999). Pile Responses Caused by Tunneling. J. Geotechnical Geoenvironmental Eng. 125, 207-215. doi:10.1061/ (asce) 1090-0241(1999)125:3(207)

Cheng, C. Y., Dasari, G. R., Chow, Y. K., Leung, C. F., and Rosser, H. B. (2007). Finite Element Analysis of Tunnel-Soil-Pile Interaction Using Displacement Controlled Model. Tunnelling Underground Space Techn. 22, 450-466. doi:10.1016/j.tust.2006.08.002

Hoek, E. (2001). Big Tunnels in Bad Rock. J. Geotech. Geoenviron. Eng. 127 (9), 726-740. doi:10.1061/(asce) 1090-0241(2001)127:9(726)

Jiang, A. N., Li, P., and Shi, H. T. (2011). Shallow Depth of the Tunnel Excavation Response Research Based on CRD Method. Proc. Eng. 15, 4852-4856. doi:10.1016/j.proeng.2011.08.905

Jun, H., and Lingling, J. (2015). "Research on the Influence for Stability of Surrounding Rock between Two-step Method and CRD Method," in Proceedings of the AASRI International Conference on Industrial Electronics and Applications (London,UK: IEA 2015), 25-28. doi:10.2991/ iea-15.2015.3

Klein, S., Sun, Y. M., and Cooney, E. (2008). "NATM/SEM Analyses for San Francisco's Transbay Extension Tunnel," in Proceedings of the North American Tunneling Conference (NAT 2008) (Littleton, Colorado: Society for Mining, Metallurgy, and Exploration, san Francisco, USA), 279-287.

Lee, C. J., and Chiang, K. H. (2007). Reponses of Single Piles to Tunneling-Induced Soil Movements in sandy Ground. Can. Geotechnical J. 44, 1224-1241. doi:10.1139/ T07-050

Lee, C. J., and Jacobsz, S. W. (2006). The Influence of Tunneling on Adjacent Piled Foundations. Tunn. Undergr. Sp. Tech. 21 (3-4), 430. doi:10.1016/ j.tust.2005.12.072

Lei, Z. Y., and Zhou, S. H. (2006). Analysis of Dismantling Temporary Support of Shallow-Depth Large-Span Tunnel. Eng. Mech. 23 (9), 120-124. doi:10.1016/ S1005-8885(07)60042-9 dismantling temporary support and so improve the safety of tunnel construction.

\section{DATA AVAILABILITY STATEMENT}

The original contributions presented in the study are included in the article/Supplementary Material, further inquiries can be directed to the corresponding author.

\section{AUTHOR CONTRIBUTIONS}

Professor GS and SW are responsible for data analysis and paper writing; FW, SL and ZW are responsible for indoor model test and numerical analysis.

\section{FUNDING}

This work is supported by National Natural Science Foundation of China (51778109) and Training plan for young backbone teachers in Colleges and universities of Henan Province (2020GGJS035).

Li, W. J., Jia, X. Y., and Liu, Z. C. (2007). Research on Construction Mechanical Behavior of Large-Cross Section Tunnel in Subway Engineering. Chin. J. Undergr. Space Eng. 3 (1), 40-43.

Liu, T., Zhao, S. Z., and Sun, F. F. (2014). Security Analysis of Dismantling Temporary Supports of Large-Span Shallow Tunnel in Upper-Soft and Lower-Hard Stratum. Rock Soil Mech. 35 (S1), 306-310. doi:10.16285/ j.rsm.2014.s1.035

Luo, Y., Chen, J., Huang, P., Tang, M., Qiao, X., and Liu, Q. (2017). Deformation and Mechanical Model of Temporary Support Sidewall in Tunnel Cutting Partial Section. Tunnelling Underground Space Techn. 61, 40-49. doi:10.1016/ j.tust.2016.09.007

Narasaki, M., Takizawa, M., Tsuchiya, Y., and Nagai, K. (1989). The Development of a CRD Method for the Purpose of Controlling the Surface Subsidence- for Urban Tunnels, as an Example of Application. Proceedings of the International Congress on Progress and Innovation in Tunnelling Toronto, ITA 1, 375-380.

Seki, J., Okda, M., Inoue, H., and Miwa, T. (1989). “Adaptability of Upper Half Vertical Subdivision Method to Flat and Large Diameter Tunnel Construction," in Proceeding of the International Congress on Progress and Innovation in Tunneling (Toronto, Canada: NRC Research), Vol. 1, 393-400.

Sharifzadeh, M., Kolivand, F., Ghorbani, M., and Yasrobi, S. (2013). Design of Sequential Excavation Method for Large Span Urban Tunnels in Soft Ground Niayesh Tunnel. Tunnelling Underground Space Techn. 35, 178-188. doi:10.1016/j.tust.2013.01.002

Shi, S. (2014). Study on Seepage Failure Mechanism and Risk Control of Water Inrush Induced by Filled Disaster Structure in Deep-Long Tunnel Located at Three Gorges Reservoir. Jinan, China: Shandong University. Ph.D. dissertation.

Soomro, M. A., Ng, C. W. W., Memon, N. A., and Bhanbhro, R. (2018). Lateral Behaviour of a Pile Group Due to Side-By-Side Twin Tunnelling in Dry Sand: 3D Centrifuge Tests and Numerical Modelling. Comput. Geotechnics 101, 48-64. doi:10.1016/j.compgeo.2018.04.010

Yoo, C. (2013). Interaction between Tunneling and Bridge Foundation - A 3D Numerical Investigation. Comput. Geotechnics 49, 70-78. doi:10.1016/ j.compgeo.2012.11.005

Wang, Z. Z., Lu, F., Xu, G. Y., and Qiu, W. G. (2018). Analysis of the Displacement Increment Induced by Removing Temporary Linings and Corresponding 
Countermeasures. Tunnelling Underground Space Techn. 73, 236-243. doi:10.1016/j.tust.2017.12.025

Zhang, J. G., Wang, M. N., Luo, L. S., and Ji, Y. L. (2009). Analysis of Influence of Dismantling Temporary Supports on Preliminary Lining of Large-Span Shallow Tunnel. Rock Soil Mech. 30 (2), 497-502. doi:10.16285/ j.rsm.2009.02.019

Zhang, Q. Y., Li, S. C., Guo, X. H., Li, Y., and Wang, H. P. (2008). Research and Development of New Typed Cementitious Geotechnical Similar Material for Iron crystal Sand and its Application. Rock Soil Mech. 29 (8), 2126-2130. doi:10.16285/ j.rsm.2008.08.002

Zhou, S. H., Zhang, X. F., She, C. G., and Yang, L. C. (2005). Study on Excavation Method under Shallow Overburden of Soft-Flow Ground. Chin. J. Rock Mech. Eng. 24 (3), 526-531. doi:10.1007/s11769-005-0030-x

Conflict of Interest: Author SL was employed by company Beijing General Municipal Engineering Design and Research Institute Co., Ltd.
The remaining authors declare that the research was conducted in the absence of any commercial or financial relationships that could be construed as a potential conflict of interest.

Publisher's Note: All claims expressed in this article are solely those of the authors and do not necessarily represent those of their affiliated organizations, or those of the publisher, the editors, and the reviewers. Any product that may be evaluated in this article, or claim that may be made by its manufacturer, is not guaranteed or endorsed by the publisher.

Copyright $\odot 2021$ Sheng, Wen, Wu, Liu and Wang. This is an open-access article distributed under the terms of the Creative Commons Attribution License (CC BY). The use, distribution or reproduction in other forums is permitted, provided the original author(s) and the copyright owner(s) are credited and that the original publication in this journal is cited, in accordance with accepted academic practice. No use, distribution or reproduction is permitted which does not comply with these terms. 